Available online at http://jurnal.stmikroyal.ac.id/index.php/jurteksi

\title{
PENENTUAN KELAYAKAN JAGUNG BIJI UNTUK PAKAN TERNAK DENGAN METODE FUZZY SAW
}

\author{
Widiarti Rista Maya ${ }^{1}$, \& Ahmad Fitri Boy ${ }^{2}$ \\ ${ }^{1,2}$ Sistem Informasi, STMIK Triguna Dharma \\ email: widiartirm87@gmail.com
}

\begin{abstract}
In the decision making process of the feasibility of corn raw materials so far only see the physical raw materials tend to be subjective so that in the decision making process of the feasibilityof corn raw materials must take a long time, sometimes the decision taken is not appropriate so that this needs to be addressed again for the feasibility of corn raw materials. From the description above need to be made an auxiliary program for decision support system by using fuzzy SAW ( Simple Additive Weighting ) method in determining corn raw material that is acceptable to PT. Charoen Phokpand Indonesia. Program which will be made more to assist manager or staff in taking decision and not replace it. The results of this study are expected to assist managers or staff in making decisions for the process of assessing the feasibility of corn raw materials in PT. Charoen Phokpand Indonesia so as to improve the quality of human resources.
\end{abstract}

Keywords: corn raw materials, decision support system, fuzzy saw method

\begin{abstract}
Abstrak: Dalam proses pengambilan keputusan kelayakan bahan baku jagung selama ini hanya melihat fisik bahan baku yang cenderung subjektif sehingga dalam proses pengambilan keputusan kelayakan bahan baku jagung harus membutuhkan waktu yang cukup lama, terkadang keputusan yang diambil tidak tepat sehingga hal ini perlu dibenahi lagi untuk proses pengambilan keputusan kelayakan bahan baku jagung. Dari uraian diatas perlu dibuat suatu program bantu untuk sistem pendukung keputusan dengan menggunakan metode fuzzy SAW (Simple Additeve Weighting) dalam menentukan bahan baku jagung yang layak diterima pada PT. Charoen Phokpand Indonesia. Program yang akan dibuat lebih bersifat untuk membantu manager atau staff dalam pengambilan keputusan dan bukan menggantikannya. Hasil dari penelitian ini diharapkan dapat membantu manager atau staff dalam mengambil keputusan untuk proses penilaian kelayakan bahan baku jagung pada PT. Charoen Phokpand Indonesia sehingga dapat meningkatkan kualitas sumber daya manusia.
\end{abstract}

Kata kunci: Bahan baku jagung, Sistem Pendukung Keputusan, metode fuzzy SAW

\section{PENDAHULUAN}

PT. Charoen Phokpand Indonesia merupakan sebuah perusahaan yang berdomisili di Medan dan bergerak di bidang pembuatan pakan ternak. Seiring dengan tingkat persaingan yang semakin ketat di bidang pakan ternak maka PT. Charoen Phokpand Indonesia dengan cara mengkaji ulang tujuan strategi dalam 
Available online at http://jurnal.stmikroyal.ac.id/index.php/jurteksi

persaingan. Tentu saja hal yang perlu dikaji dalam hal ini adalah kualitas bahan baku jagung oleh karena itu dilakukanlah penelitian ini untuk menetukan kualitas bahan baku jagung mana yang akan ditolak dan bahan baku jagung mana yang akan diterima yang nantinya akan dijadikan sebagai bahan baku dalam pembuatan pakan ternak.

Dalam menentukan kualitas bahan baku jagung ini, akan diterapkan metode Fuzzy SAW. Metode Fuzzy SAW ini dipilih karena metode ini menentukan nilai bobot untuk setiap criteria yang ditentukan, kemudian dengan proses perangkingan akan menyeleksi alternatif yang terbaik dari sejumlah alternatif yang ada dan dalam penelitian ini yang menjadi alternatif adalah jenis bahan baku jagung yang memiliki kualitas bahan baku yang terbaik berdasarkan kriteria-kriteria yang telah ditentukan.

Berdasarkan kriteria tersebut, maka Departemen Quality Control PT. Charoen Phokpand Indonesia melakukan pengecekan sample yang bertujuan untuk mengetahui kondisi bahan baku khususnya Jagung Biji yang layak diterima pada PT. Charoen Phokpand Indonesia. Pengecekan sampel ini biasanya dilaksanakan ketika bahan baku Jagung Biji akan dibeli oleh PT. Charoen Phokpand Indonesia. Hasil dari pengecekan sample yang dilakukan akan menjadi bahan pertimbangan untuk menentukan layak atau tidak bahan baku yang akan di terima oleh PT. Charoen Phokpand Indonesia khususnya pada bagian Pembelian (Purchasing) yaitu salah satu bagian dari Departement yang bertugas membeli bahan baku Jagung Biji untuk di produksi. Salah satu hal yang harus dipertimbangkan adalah kualitas jagung yang meliputi kadar air (moisture), kadar jamur (moldy seed), kadar biji mati (damage seed) yang akan dibeli dan harga beli jagung biji. Misalkan dari hasil pengecekan sample dari salah satu supplier tersebut menunjukan kadar air diatas 30\% maka pihak pembelian (purchasing) tidak memebeli jagung dari supplier tersebut dan dapat disimpulkan bahwa jagung dari supplier tersebut tidak layak diterima pada PT. Charoen Phokpand Indonesia.

Dengan mempertimbangkan kualitas jagung yang meliputi kadar air (moisture), kadar jamur (moldy seed), kadar biji mati (damage seed) dan kadar biji pecah (broken seed) jagung biji maka peneliti dalam penelitian ini merancang sebuah Decision Support System (DSS) atau Sistem Pendukung Keputusan (SPK) dalam menentukan bahan baku jagung yang layak diterima pada PT. Charoen Phokpand Indonesia dengan metode Fuzzy SAW.

\section{METODOLOGI}

\section{Analisis Permasalahan}

Sebagai perusahaan pengolah bahan pangan, semestinya perusahaan dapat menyediakan bahan baku yang berkualitas, dimana jagung merupakan bahan baku yang digunakan perusahaan. Pengadaan bahan baku jagung dapat diamati kualitas dari beberapa kriteria pada jagung. Sehingga untuk menghasilkan kualitas produksi bahan pangan yang bermutu tinggi diperlukanlah bahan baku jagung yang berkualitas sangat bagus, sehingga dengan hasil penilaian jagung yang bermutu merupakan acuan perusahaan untuk menyediakan bahan baku yang diperlukan.

\section{Algoritma Sistem}

Algoritma adalah kumpulan urutan perintah yang menentukan operasioperasi tertentu yang diperlukan untuk menyelesaikan suatu masalah ataupun mengerjakan suatu tugas tertentu. Algoritma yang digunakan adalah Fuzzy Simple Addictive Weighted (SAW)

$$
\text { Adapun langkah langkah }
$$

algoritma Fuzzy SAW adalah sebagai berikut: (1) Tahap Fuzzyfikasi, (2) Pembentukan aturan dasar data fuzzy, (3) 
Available online at http://jurnal.stmikroyal.ac.id/index.php/jurteksi

Komponen Aturan, (4) Pembobotan, (4) Normalisasi, (5) Perangkingan.

Dalam penentuan peringkat (ranking) kualitas bahan baku jagung, seperti telah dijelaskan secara mendetail sebelunnya, bahwa terdapat aspek yang menentukan, klasifikasinya sebagai berikut: (1) Aspek Moisture, (2) Aspek Broken Seed, (3) Aspek Demage Seed, (4) Aspek Moldy Seed

Tabel 1.Tabel Kriteria

\begin{tabular}{cccc}
\hline $\begin{array}{c}\text { Kode } \\
\text { Kriteria }\end{array}$ & Keterangan & Bobot & Unit \\
\hline K001 & Moisture & 0,35 & $\%$ \\
\hline K002 & Broken Seed & 0,3 & $\%$ \\
\hline K003 & $\begin{array}{c}\text { Demage } \\
\text { Seed }\end{array}$ & 0,2 & $\%$ \\
\hline K004 & Moldy Seed & 0,15 & $\%$ \\
\hline
\end{tabular}

Kemudian menggambarkan fungsi keanggotaan yang menunjukkan pemetaan titik-titik input data kedalam nilai anggotanya, yaitu rendah (R), cukup (C), tinggi ( $\mathrm{T}$ ), dan sangat tinggi (ST),seperti terlihat pada gambar 1 sebagai berikut:

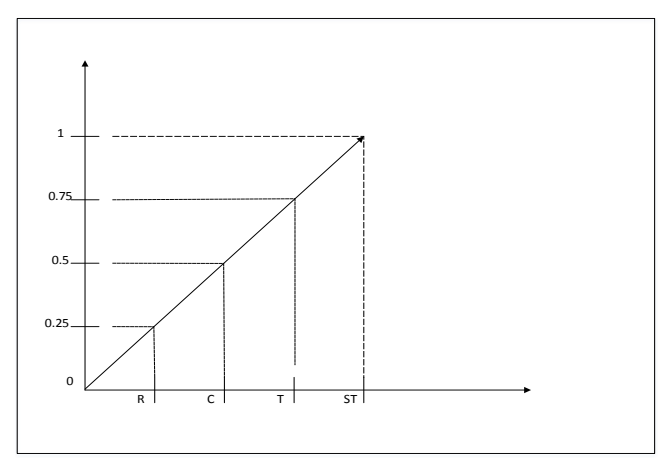

Gambar 1. Grafik Bilangan Untuk Himpunan Fuzzy

Keterangan:

R : Buruk, C : Cukup, B : Baik, ST : Sangat Baik

Dari gambar 1, bilangan-bilangan fuzzy dapat dikonversikan kebilangan crisp. Untuk lebih jelas, data bobot dibentuk dalam tabel 2 .
Tabel 2.Tabel Bobot

\begin{tabular}{cc}
\hline Kriteria & Keterangan \\
\hline Buruk $(\mathrm{R})$ & 0,25 \\
\hline Cukup $(\mathrm{C})$ & 0,5 \\
\hline Baik $(\mathrm{B})$ & 0,75 \\
\hline Sangat Baik $(\mathrm{SB})$ & 1 \\
\hline
\end{tabular}

Perhitungan Fuzzy yaitu pengubahan nilai tegas ke nilai fuzzy. Variabel bobot Moisture dikonversikan dengan bilangan fuzzy pada tabel 3 .

Tabel 3.Kriteria Bobot Moisture

\begin{tabular}{|c|c|c|c|}
\hline $\begin{array}{c}\text { Nilai } \\
\text { Mois- } \\
\text { ture }\end{array}$ & $\begin{array}{c}\text { Bilangan } \\
\text { Fuzzy }\end{array}$ & Nilai & $\begin{array}{c}\text { Semesta } \\
\text { Pembi- } \\
\text { caraan }\end{array}$ \\
\hline $15-20$ & $\begin{array}{l}\text { Sangat } \\
\text { Baik }\end{array}$ & 1 & \multirow{4}{*}{$15-35$} \\
\hline $21-25$ & Baik & 0,75 & \\
\hline $26-30$ & Cukup & 0,5 & \\
\hline $31-35$ & Buruk & 0,25 & \\
\hline
\end{tabular}

Variabel bobot Broken (K2) dikonversikan dengan bilangan fuzzy pada tabel 4 .

Tabel 4. Kriteria Bobot Broken

\begin{tabular}{cccc}
\hline $\begin{array}{c}\text { Nilai } \\
\text { Broken } \\
\text { Seed }\end{array}$ & $\begin{array}{c}\text { Bilangan } \\
\text { Fuzzy }\end{array}$ & Nilai & $\begin{array}{c}\text { Semesta } \\
\text { Pembi- } \\
\text { caraan }\end{array}$ \\
\cline { 1 - 3 }$>0-1.0$ & $\begin{array}{c}\text { Sangat } \\
\text { Baik }\end{array}$ & \multicolumn{1}{c}{1} & \\
\cline { 1 - 3 } $1.1-2.0$ & Baik & 0,75 & $0-4.0$ \\
\cline { 1 - 3 } $2.1-3.0$ & Cukup & 0,5 & \\
\cline { 1 - 2 } $3.1-4.0$ & Buruk & 0,25 & \\
\hline
\end{tabular}

Variabel bobot Demage (K3) dikonversikan dengan bilangan fuzzy pada tabel 5.

Tabel 5. Kriteria Bobot Broken

\begin{tabular}{cccc}
\hline $\begin{array}{c}\text { Nilai } \\
\text { Damage } \\
\text { Seed }\end{array}$ & $\begin{array}{c}\text { Bilangan } \\
\text { Fuzzy }\end{array}$ & Nilai & $\begin{array}{c}\text { Semesta } \\
\text { Pembi- } \\
\text { caraan }\end{array}$ \\
\cline { 1 - 3 }$>0-2.0$ & $\begin{array}{c}\text { Sangat } \\
\text { Baik }\end{array}$ & \multicolumn{1}{c}{1} & \\
\cline { 1 - 3 } $2.1-4.0$ & Baik & 0,75 & $0-8.0$ \\
\cline { 1 - 3 } $4.1-6.0$ & Cukup & 0,5 & \\
\cline { 1 - 2 } $6.1-8.0$ & Buruk & 0,25 & \\
\hline
\end{tabular}


Available online at http://jurnal.stmikroyal.ac.id/index.php/jurteksi

Variabel bobot Moldy (K4) dikonversikan dengan bilangan fuzzy pada tabel 6 .

Tabel 6. Kriteria Bobot Moldy

\begin{tabular}{cccc}
\hline $\begin{array}{c}\text { Nilai } \\
\text { Moldy } \\
\text { Seed }\end{array}$ & $\begin{array}{c}\text { Bilangan } \\
\text { Fuzzy }\end{array}$ & Nilai & $\begin{array}{c}\text { Semesta } \\
\text { Pembi- } \\
\text { caraan }\end{array}$ \\
\cline { 1 - 3 }$>0-1.0$ & $\begin{array}{c}\text { Sangat } \\
\text { Baik }\end{array}$ & 1 & \\
\cline { 1 - 3 } $1.1-2.0$ & Baik & 0,75 & \multirow{2}{*}{$0-5.0$} \\
\cline { 1 - 3 } $2.1-3.0$ & Cukup & 0,5 & \\
\cline { 1 - 2 } $3.1-5.0$ & Buruk & 0,25 & \\
\hline
\end{tabular}

\section{Fuzzyfikasi Query}

Fuzzyfikasi Query diasumsikan sebuah query konvensional (nonfuzzy) yang akan mencoba membuat dan menerapkan sebuah sistem dasar logika query. Data bahan baku jagung tertuang dalam tabel 7 dan tanel 8 .

Berdasarkan data bahan baku jagung yang tersedia pada tabel 8 dapat dibentuk matriks keputusan $\mathrm{X}$ yang telah dikonversikan dengan bilangan fuzzy pada tabel 9.

Kemudian melakukan normalisasi matriks berdasarkan persamaan yang disesuaikan dengan jenis atribut sehingga diperoleh matriks ternormalisasi R. Membuat matriks keputusan X.

Tabel 7. Data Bahan Baku Jagung

\begin{tabular}{cccccc}
\hline ID Alternatif & Nama Jagung & Moisture & Broken & Demage & Moldy \\
\hline JG001 & Jagung 1 & 24 & 1 & 4 & 1 \\
\hline JG002 & Jagung 2 & 33 & 1.2 & 2.4 & 1 \\
\hline JG003 & Jagung 3 & 35 & 4.0 & 4 & 2 \\
\hline JG004 & Jagung 4 & 35 & 3.3 & 8 & 1 \\
\hline JG005 & Jagung 5 & 16 & 3.9 & 7 & 2 \\
\hline \multicolumn{7}{c}{ Tabel 8. Data Hasil Fuzzyfikasi Query } & & \\
\hline ID Alternatif & $\begin{array}{c}\text { Nama Jagung } \\
\text { (Alternatif) }\end{array}$ & Moisture & Broken & Demage & Moldy \\
\hline JG001 & Jagung 1 & 0.75 & 1 & 0.5 & 1 \\
\hline JG002 & Jagung 2 & 0.25 & 0.75 & 0.75 & 1 \\
\hline JG003 & Jagung 3 & 0.25 & 0.25 & 0.5 & 0.75 \\
\hline JG004 & Jagung 4 & 0.25 & 0.25 & 0.25 & 1 \\
\hline JG005 & Jagung 5 & 1 & 0.25 & 0.25 & 0.75 \\
\hline
\end{tabular}

Tabel 9.Data Rating Kecocokan Setiap Alternatif Pada Setiap Kriteria

\begin{tabular}{cccccc}
\hline \multirow{2}{*}{ No } & \multirow{2}{*}{ Alternatif } & \multicolumn{5}{c}{ Kriteria } \\
\cline { 3 - 6 } & & C1 & C2 & C3 & C4 \\
\hline 1 & JG001 & 0.75 & 1 & 0.5 & 1 \\
\hline 2 & JG002 & 0.25 & 0.75 & 0.75 & 1 \\
\hline 3 & JG003 & 0.25 & 0.25 & 0.5 & 0.75 \\
\hline 4 & JG004 & 0.25 & 0.25 & 0.25 & 1 \\
\hline 5 & JG005 & 1 & 0.25 & 0.25 & 0.75 \\
\hline
\end{tabular}


Available online at http://jurnal.stmikroyal.ac.id/index.php/jurteksi

$X=\left\{\begin{array}{cccc}0,75 & 1 & 0,5 & 1 \\ 0,25 & 0,75 & 0,75 & 1 \\ 0,25 & 0,25 & 0,5 & 0,75 \\ 0,25 & 0,25 & 0,25 & 1 \\ 1 & 0,25 & 0,25 & 0,75\end{array}\right\}$

Pertama, dilakukan normaslisasi matrik $\mathrm{X}$ untuk menghitung nilai masing-masing kriteria berdasarkan kriteria diasumsikan sebagai berikut:

$$
\operatorname{Rij}\left\{\frac{\frac{X i j}{M a x X i j} \text { ijkajadalahatribut benefit }}{\frac{M i n k y}{X i j} \text { :jikajadalahatribut cost }}\right\}
$$

Keterangan:

rij : nilai ranting kinerja ternormalisasi

Xij : nilai atribut yang dimiliki dari setiap kriteria

Max Xij : nilai terbesar dari setiap kriteria

Mix Xij : nilai terkecil dari setiap kriteria

$R=\left\{\begin{array}{cccc}0,75 & 1 & 0,667 & 1 \\ 0,25 & 0,75 & 1 & 1 \\ 0,25 & 0,25 & 0,667 & 0,75 \\ 0,25 & 0,25 & 0,333 & 1 \\ 1 & 0,25 & 0,333 & 0,75\end{array}\right\}$

Hasil akhir diperoleh dari proses perankingan yaitu penjumlahan dari perkalian matriks ternormalisasi $\mathrm{R}$ dengan vektor bobot sehingga diperoleh nilai terbesar yang dipilih sebagai alternatif terbaik (Ai) sebagai solusi. Selanjutnya akan dibuat perkalian matriks $\mathrm{W}^{*} \mathrm{R}$ dan penjumlahan hasil perkalian untuk memperoleh alternatif terbaik dengan melakukan perangkingan nilai terbesar sebagai berikut :

$$
\mathrm{Vi}=\sum_{j=1}^{n}=W j r i j
$$

\section{Keterangan:}

$\mathrm{Vi}$ : ranking untuk setiap alternatif

Wj: nilai bobot dari setiap kriteria

Rij: nilai rating kinerja ternormalisasi

$\mathrm{V} 1=(0,75)(0,3)+(1)(0,35)+(0,667)(0,20)+(1)(0,15)$ $=0,858$

$\mathrm{V} 2=(0,25)(0,3)+(0,75)(0,35)+(1)(0,20)+(1)(0,20)$ $=0,688$

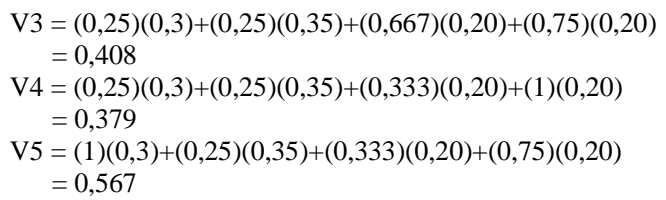

\section{HASIL DAN PEMBAHASAN}

Setelah melakukan pengujian, untuk hasil/output berupa nilai hasil perhitungan dan keputusan yang di berikan sistem, maka Hasil Perang-kingan diperoleh pada tabel 10 .

Tabel 10 Data Perangkingan

\begin{tabular}{cccc}
\hline $\begin{array}{c}\text { Alterna- } \\
\text { tif } \\
(\mathbf{A i})\end{array}$ & $\begin{array}{c}\text { Nilai } \\
\text { Akhir }\end{array}$ & Ranking & Ket \\
\hline JG001 & 0,858 & 1 & Layak \\
\hline JG002 & 0,688 & 2 & Layak \\
\hline JG003 & 0,408 & 4 & $\begin{array}{c}\text { T idak } \\
\text { Layak }\end{array}$ \\
\hline JG004 & 0,379 & 5 & $\begin{array}{c}\text { Tidak } \\
\text { Layak }\end{array}$ \\
\hline JG005 & 0,567 & 3 & Layak \\
\hline
\end{tabular}

Berdasarkan hasil perhitungan metode fuzzy saw dapat di lihat bahwa rentang nilai bahan baku jagung yang layak diterima sebesar 0,5 keatas sedangkan yang tidak layak diterima lebih kecil dari 0,5, dengan demikian alternatif JG001 dan JG002 adalah Alternatif yang terpilih sebagai Alternatif terbaik.

\section{SIMPULAN}

Walaupun program ini hanya menggunakan parameter panilaian yang sedikit, tetapi program ini masih dapat di kembangkan dengan menambahkan parameter penilaian yang lebih banyak sesuai kebutuhan pengambil keputusan.

Penggunaan Metode Fuzzy SAW 
Available online at http://jurnal.stmikroyal.ac.id/index.php/jurteksi

dalam penelitian ini mampu memberikan hasil keputusan dalam menentukan barang yang dapat diretur berdasarkan perhitungan metode tersebut

\section{DAFTAR PUSTAKA}

Kusrini. (2007). Konsep Dan Aplikasi Sistem Pendukung Keputusan. Yogyakarta: Andi

Kusuma, S. \& Purnomo, H. (2006). Aplikasi Logika Fuzzy untuk
Pendukung Keputusan.

Yogyakarta: Graha Ilmu.

Purnomo \& Kusumadewi. (2010). Aplikasi Logika Fuzzy Untuk Pendukung Keputusan. Yogyakarta: Graha Ilmu. 
Available online at http://jurnal.stmikroyal.ac.id/index.php/jurteksi 
Jurnal Pena Edukasi

Vol. 4 No. 2, Maret 2017
ISSN 2407-0769 e-ISSN 2549-4694 